\title{
"Sorgenkind des Lebens": cuidado, interioridad y embriaguez en La montaña mágica. Una interpretación blochiana
}

\author{
"Sorgenkind des Lebens". Care, Inwardness and Ecstasy \\ in The Magic Mountain: a Blochian Reading
}

\section{"Sorgenkind des Lebens": cuidado, interioridade e embriaguez em $A$ montanha mágica. Uma interpretação blochiana}

María Belforte
Universidade de Buenos Aires (UBA), Cidade Autônoma de Buenos Aires, Argentina.
E-mail: mariabelforte@yahoo.com

\begin{abstract}
Resumen: El presente artículo analiza las nociones de cuidado (Sorge), interioridad (Innerlichkeit) y embriaguez (Rausch) en La montaña mágica (1924), de Thomas Mann. El estudio se plantea a partir de las interpretaciones literarias y filosóficas de Ernst Bloch sobre la República de Weimar y se propone mostrar las transformaciones e implicancias ideológicas de estos conceptos en la novela.
\end{abstract}

Palabras clave: embriaguez, interioridad, cuidado, Bildungsroman, República de Weimar.

\begin{abstract}
This paper analyzes the concepts of care (Sorge), inwardness (Innerlichkeit) and ecstasy (Rausch) in The Magic Mountain (1924), by Thomas Mann. It deals with the philosophical and literary interpretations that Ernst Bloch developed about the Weimar Republic and aims at showing the transformations and ideological consequences of said concepts in the novel.
\end{abstract}

Keywords: Ecstasy, Inwardness, Care, Bildungsroman, Weimar Republic. 
Resumo: O presente artigo analisa as noções de cuidado (Sorge), interioridade (Innerlichkeit) e embriaguez (Rausch) em A montanha mágica (1924), de Thomas Mann. O estudo é baseado nas interpretações literárias e filosóficas realizadas por Ernst Bloch sobre a República de Weimar e propõe-se a discutir as transformações e implicações ideológicas desses conceitos no romance.

Palavras-chave: embriaguez, interioridade, cuidado, Bildungsroman, República de Weimar.

Submetido em 28 de agosto de 2020.

Aceito em 06 de outubro de 2020.

Publicado em 17 de dezembro de 2020. 
"Sorgenkind des Lebens": cuidado, interioridad y embriaguez en La montaña mágica... María Belforte

\section{Introducción}

El cuidado constituye un tema central en una de las novelas de Thomas Mann más destacada y reconocida. La montaña mágica, publicada en 1924, compone en su narración un entramado que vincula la enfermedad con problemas existenciales y metafísicos: el amor, el tiempo, la muerte. La literatura crítica ha abordado la obra desde múltiples perspectivas que retoman tanto los aspectos relativos a la tensión de las fuerzas de lo apolíneo y lo dionisíaco como los antecedentes filológicos de su composición o la construcción formal de su narrativa. ${ }^{1}$ Desde un punto de vista histórico, con especial atención a una historia de los conceptos, la obra constituye un caso sobresaliente de la literatura de Weimar ${ }^{2}$ y responde con ella a uno de los problemas destacados que obsesionan ${ }^{3}$ a los intelectuales de la República: la embriaguez (Rausch).

El concepto de Rausch, cuyos importancia en la filosofía de Nietzsche se bifurca ya comenzado el siglo XX en una constelación ramificada de significaciones, se encuentra fuertemente presente durante el período de entreguerras en los intelectuales y literatos vinculados a la poesía de Stefan George y su círculo, como también en autores cuya recepción del filósofo derivó en una producción original y propia atravesada por sus categorías. ${ }^{4}$ Thomas Mann no constituyó una excepción a esta tendencia y su intervención política reunida en Betrachtungen eines Unpolitischen es fiel reflejo de esta presencia. ${ }^{5}$ La construcción de La montaña mágica se

\footnotetext{
1 En relación con la complejidad del texto y su recepción puede consultarse "Der Zauberberg", (MAX, 2015, pp. 32-42).

2 En su estudio del período, Peter Gay sostiene que La montaña mágica posee un "significado sintomático importante" para la República de Weimar (2001, p. 123).

3 Lebovic caracteriza esta actitud hacia el Rausch como una verdadera obsesión para algunos filósofos de la vida, en especial para Ludwig Klages, figura intelectual destacada durante la República (LEBOVIC, 2013, p. 92). En adelante se conserva el término Rausch o se traduce como "embriaguez", aunque resulta importante advertir sobre la polisemia del término en alemán, de la que se intenta dar cuenta a lo largo del presente artículo.

4 Pueden mencionarse ejemplos tan diversos como los de Gottfried Benn o Ernst Jünger. En su pormenorizado estudio de la recepción de Nietzsche en Alemania, Aschheim retoma palabras del primero en relación a la influencia de Nietzsche en los expresionistas: “'En realidad, todo lo que mi generación discutió, con lo que se ocupó internamente, puede decirse sufrió, también se puede decir, amplió, todo lo que había sido expresado y agotado ya había encontrado formulación definitiva en Nietzsche, todo lo posterior fue exégesis. [...]"' (ASCHHEIM, 2000, p. 65). Para las citas al español se ha recurrido a traducciones disponibles que se indican en la sección bibliográfica final; cuando no se menciona traductor se trata de una traducción propia.

5 Aschheim sostiene, en relación a la recepción de Nietzsche en esta obra que, junto con el libro de Ernst Bertram, Nietzsche. Versuch einer Mythologie ambos aparecidos en 1918, constituyen las dos construcciones más sofisticadas que emergen a partir de la guerra y que expresan la visión característica de muchos intelectuales (ASCHHEIM, 2000, p. 151).
} 
"Sorgenkind des Lebens": cuidado, interioridad y embriaguez en La montaña mágica... María Belforte

encuentra temporalmente atravesada por la elaboración de estas intervenciones de Mann en la Gran Guerra y compone un singular modo de enfrentar el problema del concepto de Rausch, vinculado a una particular concepción de la interioridad y el cuidado en el complejo contexto de la República.

En La montaña mágica, Mann aborda el conflicto del Rausch desde una mirada irónica que hace entrar en diálogo la experiencia dionisíaca con el discurso racional del cuidado. Hans Canstorp es "ein Sorgenkind des Lebens" y con esta construcción nominal, que atraviesa varios capítulos de la novela, el autor pone en juego el problema de la existencia y el concepto de vida en clave humorística. Este epíteto del héroe remite a otro elemento fundamental de la configuración de la novela: la tradición de la Bildungsroman y la constelación subjetiva de la interioridad que le es inherente como trasfondo de la narración.

El presente artículo se propone analizar a partir del concepto de Rausch el trabajo de construcción del problema existencial en la novela de 1924 para mostrar cómo se descompone allí la imagen de la interioridad burguesa: la subjetividad de la inteligencia alemana, enmarcada por los cambios tecnológicos de las primeras décadas del siglo, responde con una renovación ideológica de la interioridad que en la novela de 1924 se muestra de forma paradigmática.

\section{El problema del Rausch en La montaña mágica: pre- sencia de una ausencia}

En un análisis de Der Zauberberg presentado en Princeton, Mann compara los orígenes de la novela con Der Tod in Venedig para mostrar un contraste entre las dos obras. La llama allí "una pieza humorística" (ein humoristisches Gegenstück) y explica que La montaña mágica fue pensada como una obra satírica en relación a la novela corta de 1912 protagonizada por Gustav Aschenbach

\footnotetext{
6 Se conserva aquí la expresión en alemán debido a la pérdida que implicaría su traducción. La construcción nominal sugiere la idea de un niño enfermizo al cuidado de la vida, y en la narración se mantiene presente incluso en el final de la novela, en la que Mann escribe sobre su protagonista: “Lebewohl, Hans Castorp, des Lebens treuherziges Sorgenkind! Deine Geschichte ist aus." (MANN, 1988, p. 756).
} 
"Sorgenkind des Lebens": cuidado, interioridad y embriaguez en La montaña mágica... María Belforte

(MANN, 1995, p. 135). El punto en común que encuentra significativo resulta de importancia para el análisis aquí propuesto. Mann sostiene sobre La montaña mágica:

Su atmósfera debía de ser la amalgama de muerte y diversión, que yo había probado en este especial localidad aquí arriba. La fascinación de la muerte, el triunfo del desorden embriagador sobre una vida consagrada al orden más elevado, que está descripto en La muerte en Venecia, debía ser traducido a un plano humorístico. Un héroe simple, el conflicto cómico entre las aventuras macabras y la honorabilidad burguesa, hasta donde llegaba mi intención (id.).

Mann se proponía una versión humorística de "la fascinación de la muerte", de lo que denomina también "el triunfo del desorden embriagador sobre una vida consagrada al orden más elevado". Se trata entonces, en el proyecto de escritura de La montaña mágica, de contar el triunfo del desorden de la embriaguez, que el escritor ya había narrado trágicamente en Der Tod in Venedig. Desde un punto de vista crítico, cabe preguntarse entonces por el interés de Mann en esta falta de orden producida por el Rausch, interés que adquiere un espacio tal que lleva a instalarlo en el centro temático en estas dos importantes obras. ${ }^{7}$

Pero si la respuesta al desorden en Der Tod in Venedig pareciera colocar al Rausch en un lugar vertebral al punto de que este llega a tomar posesión de la ordenada vida del maduro artista Aschenbach y a concluir con su muerte, en La montaña mágica el abordaje de esa desorganización de la vida se lleva a cabo mediante una neutralización de la embriaguez por medio de un proceso de racionalización. En efecto, el centro de la acción, que se construye narrativamente como el espacio y la atmósfera de "los de arriba", se encuentra mediado por las reglas de la medicina y el cuidado del sanatorio. La enfermedad y la muerte tienen allí

\footnotetext{
7 Cabe recordar aquí que el origen de la novela data de 1913. La extensión de su desarrollo, hasta su publicación en 1924, atraviesa por completo la Primera Guerra Mundial y ve el pasaje del Imperio a la República. La importancia e influencia de los acontecimientos históricos en Mann son subrayados y analizados por Vaget en su estudio de la producción de la novela (2008, pp. 14ss.).
} 
"Sorgenkind des Lebens": cuidado, interioridad y embriaguez en La montaña mágica... María Belforte

una respuesta controlada y contenida dentro del ordenamiento racional que responde a una organización científica y técnica. La muerte se incorpora como parte de la vida organizada: "Hans Canstorp fue a ver al difunto. Lo hizo en señal de rebeldía contra el principio del sanatorio de ocultar la muerte sistemáticamente, porque despreciaba ese deseo egoísta de ignorar, de no querer ver ni oír nada de los demás, y porque quería oponerse a esa costumbre con actos" (MANN, 2015, p. 423). ${ }^{8}$

Otro ejemplo sobresaliente de ello es la representación de la "interioridad" (Innerlichkeit) que en la novela se expone fisiológicamente. Tras la partida de Clawdia Chauchat, Hans Castorp reacciona de la siguiente manera:

Pálido el joven abandonado, se había dirigido de inmediato a su habitación para asomarse a la terraza y, desde arriba, ver una vez más el trineo que se deslizaba por el camino de Dorf tocando la campanilla. Luego se había arrojado sobre una silla y había sacado del bolsillo interior de su chaqueta el recuerdo que le había dado su amada, la prenda, que esta vez no consistía en unas virutitas de lapicero rojo, sino en una pequeña placa de cristal que había que mirar a contraluz para poder distinguir algo... el retrato interior de Clavdia, un retrato sin cara que, en cambio, mostraba la delicada osamenta de su tronco, sutilmente enmarcada por el fantasma de la carne, y los órganos de la cavidad torácica... (ibíd., pp. 504-505).

La interioridad de la amada es reducida a una imagen técnica que la muestra como un organismo en sus características interiores puramente materiales y físicas. La racionalización biológica de la subjetividad es conducida entonces por medio del humor. Mann descompone la oscuridad de la interioridad en fragmentos que la fisiología corporal expone de manera descarnada: “iCuántas veces habría contemplado y besado aquel retrato en el tiempo que

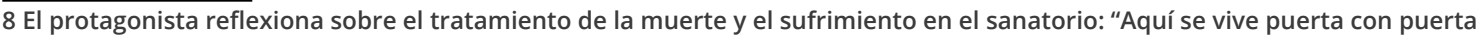
junto a personas agonizantes y con los más terribles sufrimientos y martirios. Pues bien, no solo se hace como si eso no fuera con uno, sino que encima nos protegen con sumo cuidado para que no entremos jamás en contacto con ello y veamos nada; seguro que hacen desaparecer el cadáver en secreto mientras desayunamos o almorzamos" (MANN, 2015, p. 428).
} 
"Sorgenkind des Lebens": cuidado, interioridad y embriaguez en La montaña mágica... María Belforte

había transcurrido entretanto, trayendo consigo tantos cambios!" (ibíd., p. 505). El desorden de las fuerzas interiores se resuelve por medio de la ironía: frente al desborde de la embriaguez que se representa en el amor dionisíaco hacia la exótica Frau Chauchat, el personaje principal posee la herramienta a mano de la técnica para neutralizar esta fuerza que posee los componentes de la embriaguez: el exotismo, el amor infértil, ${ }^{9}$ la destrucción del individuo. ${ }^{10}$ Con este ejemplo se descubre uno de los primeros elementos a tener en cuenta en relación a la embriaguez, que el propio Mann reconocería años más tarde como componente fundamental de su narración. Aquí, a diferencia de la atmósfera que envuelve y atrapa al protagonista de La muerte en Venecia, la embriaguez, que se expresa por ejemplo en el amor y en la enfermedad, aparece controlada por la acidez y la ironía que se introduce en la convivencia y prevalencia del discurso racional de la ciencia.

La obra posee en este sentido una forma de expresión "pedagógica y política"11 del Rausch según la cual este aparece mediado por el discurso instrumental de la técnica. Con la ironía del racionalismo científico frente al caos orgánico de la embriaguez, Mann muestra un alejamiento de la posición con la que ataca al Zivilisationsliterat ${ }^{12}$ en sus Betrachtungen eines Unpolitischen, obra que interrumpe la composición de la novela. Aunque la aproximación a la ciencia médica aparece atravesada por el humor y la acidez, el cuidado se impone como mediación que neutraliza el descontrol embriagador. En las palabras de Settembrini aparece

\footnotetext{
9 Existe una relación de lo dionisíaco con Eros: de los dos impulsos esenciales para la vida según El nacimiento de la tragedia, el más importante para Eros es el dionisíaco: "en su interior se hace notable el impulso que conduce al individuo a la superación de su individualidad, a la disolución en el todo" (OBERTHÜR, 2012, p. 171)

10 Dionisio, en tanto dios extranjero, implica desde sus orígenes un vínculo con lo bárbaro, propio de la embriaguez. Cabe recordar aquí que “con el nombre del dios 'Dionisos', Nietzsche. apunta a la dimensión indestructible y arcaica de toda cultura, olvidada por el pensamiento socrático-racionalista; apunta al Uno primordial, un fondo devorador, penetrante y desgarrador que se expresa en la forma de la figura apolínea como (auto)redención" (HUFNAGEL, 2012, p. 55). En El nacimiento de la tragedia, Nietzsche describe la potencia dionisíaca "como realidad embriagada" que "intenta incluso aniquilar al individuo y redimirlo mediante un sentimiento místico de unidad" (1977, p. 46).

11 Vaget sostiene que hacia 1915, Mann tendría ya en mente una novela que parecería ser una Bildungsroman y remite a una carta de agosto de 1915 en la que el escritor reconoce un intento “pedagógico y político" en su obra (2008, p. 19).

12 Gay resume el rol que cumple esta figura en el ensayo de 1918 de la siguiente manera: "Heinrich Mann aparece, no con su nombre, sino con un epíteto intraducible, como el Zivilisationsliterat: el literato culto pero poco profundo, devoto de los valores malditos de una civilización optimista, superficial, materialista, burguesa y racionalista, ciego a los abismos del alma humana, a los misterios de la Kultur, la seducción traicionera de la teoría del progreso, los errores de la democracia y que insiste, y esto es lo peor de todo, en corromper con la política las esferas de la cultura y del espíritu" (2001, p. 74).
} 
"Sorgenkind des Lebens": cuidado, interioridad y embriaguez en La montaña mágica... María Belforte

la asociación de la ironía con el placer, asociación propia de la dinámica de "los de arriba":

¡Se creen con derecho a la amargura, la ironía y al cinismo! “iEn este lugar de placer!" ¿No es acaso un lugar de placer? Pues claro que lo es, pero en el sentido más ambiguo de la palabra. [...] ¡Ah, sí, la ironía! ¡Guárdese usted de la ironía que aquí prolifera, ingeniero! ¡Guárdese en general de esa actitud! (MANN, 2015, p. 318).

En relación con el vínculo del Rausch con el cuerpo físico y sus condiciones orgánicas, el final del capítulo cuarto se cierra con la explicación de la embriaguez de la enfermedad en términos fisiológicos, que indica a Castorp la relación de su estado de embriaguez con los mecanismos orgánicos:

Usted enseguida se sintió un poco febril, como borracho -afirmó el consejero -. Son las toxinas creadas por los microbios las que producen ese estado embriagado del sistema nervioso central, ya me entiende, y por eso se le colorean a uno las mejillas. Comenzará por meterse en la cama, Castorp. Debemos ver si con un par de semanas de reposo lo ponemos sobrio. (ibíd., p. 262, la trad. ha sido modificada).

Este diagnóstico de la embriaguez corre en paralelo con una resignificación de la interioridad: "Tomaremos una bella panorámica de su interior. Seguramente la gustará echar un vistazo dentro de su propio cuerpo" (íd). ${ }^{13}$ El tratamiento y el cuidado de la vida en el sanatorio implican una transformación de elementos de la subjetividad.

\footnotetext{
13 La vinculación de la enfermedad con la embriaguez y el estado producido por ciertas drogas también es retomada en el diálogo de Joachim y Hans Castorp: "He hablado de una especie de envenenamiento, de autoenvenenamiento del organismo, que surge cuando se descompone una sustancia todavía desconocida y difundida por todo el cuerpo; los productos de esta descomposición nos causan una suerte de estado de embriaguez, el mismo que produce el consumo habitual de estupefacientes, de morfina o cocaína" (MANN, 2015, p. 270).
} 
"Sorgenkind des Lebens": cuidado, interioridad y embriaguez en La montaña mágica... María Belforte

\section{Respuesta racional al Rausch: el cuidado}

En el apartado "'Ontologien' der Fülle und Vergänglichkeit" (Ontologías de la plenitud y la transitoriedad) incluido en Erbschaft dieser Zeit (Herencia de esta época), Bloch se pregunta, refiriéndose a Heidegger, por qué la burguesía ha aceptado tanta oscuridad en uno de sus filósofos más de moda cuando ha incluido tanto la dispersión (Zerstreuung) como la embriaguez (Berauschung) en su interioridad (Innerlichkeit) (BLOCH, 1973, p. 308). Es decir, Bloch subraya aquí cómo la peculiar convivencia de procesos de racionalización y mitologización, tendientes a construir formas de conciencia falsa, son compatibles con una filosofía contrarrevolucionaria de la existencia. ${ }^{14}$ Pero además, pone énfasis en cómo esa filosofía de la existencia se presenta como oscuridad ontológica "atenuada" por "el placer de la contemplación". Es en este sentido que sugiere que la ontología de Heidegger responde a las distintas capas de la burguesía mediante dos conceptos centrales de su filosofía. Por medio de su concepto de angustia (Angst) se responde a las condiciones de la pequeña burguesía, por medio del concepto de cuidado o preocupación (Sorge) se afecta a las capas de la gran burguesía que son así "mantenidas en dirección a la nada" (ibíd., p. 307).

Siguiendo este análisis, se puede reconocer cómo los componentes del Rausch se relacionan con una particular respuesta al cuerpo enfermo en el contexto de La montaña mágica: la interioridad de los personajes es sometida al cuidado y a la perspectiva racional de la medicina. En la convivencia con la muerte, el cuerpo insano es mediado por la observación minuciosa y permanente de una autoridad científica. En este punto, el concepto de interioridad (Innerlichkeit) resulta clave. En los años cuarenta, György Lukács caracterizaba de la siguiente manera este componente en la historia de la cultura alemana: "Alemania fue adentrándose, pues, por la vía imperialista y la inteligencia alemana se retiró paulatinamente

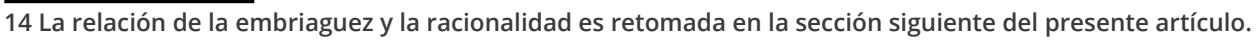


"Sorgenkind des Lebens": cuidado, interioridad y embriaguez en La montaña mágica... María Belforte

al 'pequeño mundo' de la interioridad pura, sin haber llegado a implantar realmente el humanismo burgués como cultura de la vida social en su conjunto". (1969a, p. 111). ${ }^{15}$ La "interioridad" se vuelve entonces, de acuerdo con este análisis un elemento propio de la personalidad del individuo, del sujeto enfrentado a la sociedad y no un aspecto dinámico de la dialéctica intersubjetiva y política. Es precisamente en relación con esta forma de la interioridad propia de la Bildung que, en Erbschaft dieser Zeit, Bloch observa que la ontología de Heidegger "refleja la arquitectura del interior de las capas que se hunden" (die Innenarchitektur sinkender Schichten) (1973, p. 307). Y así como esta ontología heideggeriana se constituiría en una corriente destacada de la filosofía que se consagraría más allá de la derrota del nacionalsocialismo, la obra de Mann mostraría una respuesta racional a la transformación y caída de los componentes propios de la embriaguez que habían sido puestos en juego como partes de la interioridad durante las primeras décadas del siglo XX.

En una carta hacia finales de la década del cuarenta, Mann ubica a Der Zauberberg dentro de la tradición de la Bildungsroman (1995, p. 152) ${ }^{16}$ y en otra carta, de 1922, anterior a la publicación de la novela, analiza la relación del género con el tema de la muerte y la enfermedad:

\begin{abstract}
El interés por la muerte y por la enfermedad, por lo patológico, por la decadencia es solo una forma de expresión del interés por la vida, por el ser humano, como lo muestra la facultad humanista de la medicina; quien se interesa por lo orgánico, por la vida, se interesa en efecto por la muerte; y podría ser tema de una novela de formación mostrar que la vivencia de la muerte es en última instancia una vivencia de la vida, que guía hacia el ser humano (1995, p. 30).
\end{abstract}

\footnotetext{
15 Lukács continúa: “De ahí que en Alemania tanto las tendencias ideológicas más disolventes del humanismo burgués como el inicialmente sólo subterráneo y luego más rápido y consciente impulso de la reacción decadente cobren vida de manera más pura y completa que en cualquier otro país" (1969a, p.111).

16 También en su análisis de Princeton sobre La montaña mágica vincula su obra con el género: “Lo que él [Castorp] aprende a entender es que toda salud más elevada tiene que haber pasado por las profundas experiencias de la enfermedad y la muerte, así como el conocimiento del pecado es una condición previa para la salvación, 'Hacia la vida', le dice una vez Hans Castorp a Madame Chauchat, 'hacia la vida hay dos caminos: uno es el habitual, directo y honrado. El otro es terrible, guía a través de la muerte y es el camino genial'. Esta transmisión de la enfermedad y la muerte como paso necesario hacia el saber, la salud y la vida hace a La montaña mágica una novela de iniciación" (MANN, 1995, p. 137).
} 
"Sorgenkind des Lebens": cuidado, interioridad y embriaguez en La montaña mágica... María Belforte

Se puede ver a partir de esta concepción de la vivencia de la vida una tensión: el componente desmembrante y desindividualizador del Rausch es mediado así por los elementos literarios que aportan racionalidad a un problema humano que Mann reconoce central; la legitimidad del conocimiento y de la salud, para que se constituya auténticamente como forma de redención y salvación, implica la puesta en juego de elementos de la interioridad que actúan contra el principio de individuación. La centralidad de la muerte y del problema existencial en su narración lo confirma. Pero la respuesta a esa problemática, que la embriaguez pone en juego al establecer una forma corporal de interrelación con los otros sujetos y con el mundo, no se rige con principios humanistas incorporados a la interioridad burguesa alemana, sino que se resuelve con una forma no ilustrada de esa interioridad. ${ }^{17}$ En el caso de La montaña mágica, el relativismo es consecuencia de la ironía: el humor muestra la salida racional del cuidado del otro, que la racionalidad médica propone, como un camino de grado inferior pero real, al cual se subordina la interioridad. El ideal humanista se ha despojado del contenido de trascendencia para ganar, por un lado la racionalidad instrumental del liberalismo y, por otro, la irracionalidad oscura de un existencialismo que Bloch llama "contemplativo".

Más allá de la discusión respecto del género de la obra y de la excepción que la novela constituiría, ${ }^{18}$ la vinculación a la Bildungsroman por parte del propio autor implica el reconocimiento de elementos de esta tradición en relación a conceptos y valores con los que establece una relación estrecha. Pero la dinámica que se le impone al héroe constituye una forma racional alejada del componente subjetivo propio de la tradición decimonónica. La interioridad ya no es formada en una relación del sujeto con el mundo, sino que aquí, como sostuvo Georg Lukács, "el mundo" se vuelve ausente, conminado "allí abajo", el héroe se encuentra "de vacaciones", totalmente liberado de lo cotidiano y de los problemas propios de la vida capitalista (1969b, pp. 39-40). La formación de

\footnotetext{
17 George L. Mosse pone como ejemplo a Thomas Mann para referirse al liberalismo alemán que denomina “liberalismo tímido", este no habría podido librarse del romanticismo, ni de la distinción entre civilización y Kultur (1997, p. 128).

18 Tan solo por citar un ejemplo que reconoce el vínculo con el género, se puede hacer referencia aquí a las interpretaciones de Martin Travers (2008), quien indica asimismo diferencias con el modelo clásico.
} 
"Sorgenkind des Lebens": cuidado, interioridad y embriaguez en La montaña mágica... María Belforte

la interioridad se coloca entonces en manos de una organización ideal estructurada en torno al cuidado del cuerpo enfermo, observado y sometido a nuevas leyes que excluyen los excesos. La corporalidad gana así un lugar de privilegio en la atmósfera artificial del sanatorio.

Los dos aspectos centrales de la embriaguez presentes en la novela son neutralizados por medio de los mecanismos racionales del sanatorio: el amor y la enfermedad son controlados minuciosamente por medio de la dinámica organizativa de la institución. Los tiempos y las relaciones se subordinan a distintos mecanismos en pos de la cura. Este tratamiento al que se somete el héroe se extiende asimismo al lector en una enseñanza compartida del tiempo "de arriba". En este sentido, la extensión de la novela ha sido interpretada como contrapartida de la experiencia de Castorp: "es por supuesto un principio de la 'novela de formación' alemana, el Bildungsroman, que aquello que el héroe que es educado atraviesa debe ser atravesado en detalle también por el lector. No hay por lo tanto tal cosa como un Bildungsroman corto" (REED, 2001, p. 11). Con ello se observa cómo el problema de época de la enfermedad y la muerte, la expresión del desorden de la vida que la filosofía de Nietzsche pone en juego en el siglo XIX y que dispone las bases de la filosofía y la literatura alemanas de las primeras décadas del nuevo siglo, es aquí presentada a la educación del individuo desde una perspectiva racional. La ironía y la acidez de la obra juegan un rol central que quita relevancia al contenido existencial del problema de la embriaguez.

\section{Ernst Bloch: interpretaciones de la embriaguez en la República}

Ernst Bloch se detiene a examinar el concepto de embriaguez y lo incorpora a sus lecturas de la ideología de la República de Weimar. El filósofo le otorgó importancia a la noción para la construcción de interpretaciones teóricas que desarticularan críticamente la 
"Sorgenkind des Lebens": cuidado, interioridad y embriaguez en La montaña mágica... María Belforte

dominante ideología contrarrevolucionaria en ascenso durante la década del veinte y comienzos del treinta.

También para Walter Benjamin, quien tempranamente presta atención a las elaboraciones literarias y posteriormente políticas provenientes del círculo de Stefan George, el concepto de Rausch es mencionado ya a comienzos de los años veinte en las recuperaciones que lleva a cabo para sus "Esquemas para un problema psicofísico"19 en los que retoma distintos conceptos de Ludwig Klages. Pero la construcción central para esta categoría se la da la elaboración de una constelación conceptual que tiene lugar con la unión de las significaciones pendulares de la embriaguez de esta tradición alemana con el encuentro de las imágenes presentes en la literatura y cultura francesas. El tema irá tomando en Benjamin un valor destacado, que une el arco entre lo estético y lo político al punto que llega a preguntarse en sus fragmentos de Das Passagen Werk si, a partir de la teoría de Marx del fetichismo de la mercancía, la apariencia ambigua del mundo económico capitalista no implica "una importancia hasta entonces desconocida de la embriaguez [Rausch] para la percepción, de la ficción para el pensamiento" (BENJAMIN, 2005, p. 400). La relevancia que pareciera otorgarle aquí Benjamin a la embriaguez para sus investigaciones sobre lo que denomina "la doble faz de las apariencias del siglo XIX" (íd.) se corrobora a su vez con su propia experimentación con hachís y teóricamente en distintos estudios políticos y literarios. También frente a la poesía de Baudelaire, la embriaguez obtendrá para Benjamin un sentido redimido de la dirección reaccionaria que se iba configurando en Alemania. Y aún más específicamente en el sentido programático que le otorgará a la categoría en el descubrimiento del surrealismo como corriente revolucionaria. La frase programática que estructura su análisis de esta vanguardia en 1929 resume la importancia dada por el filósofo al concepto: "Ganar las fuerzas de la embriaguez para la revolución" (GS II/1, p. 307).

19 Estas reflexiones sobre la corporalidad muestran la importancia del tema del amor y la sexualidad en Benjamin. La referencia a Klages en este contexto resulta altamente significativa. Cf. BENJAMIN, 2016, pp. 43ss. 
"Sorgenkind des Lebens": cuidado, interioridad y embriaguez en La montaña mágica... María Belforte

Otro concepto elaborado por Benjamin que en este contexto resulta relevante es el de "nihilismo médico". Benjamin encuentra en Carl Jung su último exponente y señala a las figuras de Gottfried Benn y Louis-Ferdinand Céline como representantes de este nihilismo que, indica, "ha surgido del shock que el interior del cuerpo ha producido en los que le rodean" (2005, p. 474). Este shock, del interior del cuerpo, enmarca las irónicas descripciones médicas de La montaña mágica. ${ }^{20}$

Bloch, quien comparte con su amigo Benjamin la experimentación con hachís, recurre al concepto de embriaguez para elaborar una lectura de la ideología regresiva de la República especialmente en su obra Erbschaft dieser Zeit. En este trabajo, la embriaguez es interpretada como elemento distintivo del componente arcaico puesto en juego durante el período de entreguerras. Este elemento, sostiene Bloch, se conjuga con otro de tipo racional que se manifiesta como relativismo y que actúa en alternancia con el primero. Bloch encuentra un proceso de pasaje del mundo de la dispersión al de la embriaguez especialmente en los años que van de 1927 a 1929 (1973, p. 213).

Para Bloch, la obra de Mann se destaca como exponente del aspecto racionalista que se dirige a dotar de contenidos al espacio vacío (Hohlraum) de la burguesía media; para el filósofo, esta necesitaba construcciones que representaran ficcionalmente su vida sin color y que mostrara sus ideales como si todavía valieran la pena (1973, p. 198). En este sentido, una clave para la comprensión de la ironía en Mann es su vínculo con el liberalismo, que no deja de recurrir a ella (ibíd., p. 199). Su literatura propone una galería de "vida aparente" y de preguntas pero evade una central: cuál es el verdadero origen de esta vida y posterga así su cuestionabilidad (ibíd., p. 198). Se trata de una literatura que posee una "acidez agradable" y que se dirige a estos sectores golpeados por la crisis económica. Lo que se pone en juego es una "formación culta"

20 También Eva Wessell distingue el elemento nihilista en la novela pero lo hace en una dirección que coincide solo parcialmente con la lectura aquí propuesta: "La falta de compromiso, el tratamiento humorístico de los conflictos intelectuales de la sociedad moderna, podría haber sido interpretado no como un signo de tolerancia sino como nihilista" (WESSELL, 2004, p. 141). 
"Sorgenkind des Lebens": cuidado, interioridad y embriaguez en La montaña mágica... María Belforte

(belesene Bildung) que viene a compensar posiciones económicas o sociales que no son lo suficientemente altas (íd.).

Según esta interpretación, "las preguntas permanecen en la superficie sintomática", en la que son fantaseadas, la vida allí representada según Bloch no es tan "real como su elocuencia", y la acidez se vincula con las dudas interiores burguesas (íd.). En "Poesie im Hohlraum" (Poesía en el espacio vacío), de 1931, Bloch analiza la literatura de Mann de la siguiente manera:

Pero también expertos como Wassermann, o el mismo Thomas Mann inauguraron hasta el momento solamente un modo de la apariencia abstracta y de la vida aparente con todas sus preguntas, fuera de lo real: de dónde proviene esta vida y cómo está por ende verdaderamente constituida. Ellos establecen su plus en construcciones que oscilan tan bellamente, en las cuales todo es cierto menos el mundo, que de manera aparente tan de modo realista representan (1984, p.121).

Si la intención de Mann había sido, tal como manifiesta él mismo respecto de su obra de 1924, la representación del triunfo de un "desorden embriagador", la afirmación de ese orden se daría en la novela estéticamente en convivencia con la atmósfera del cuidado y organización de la vida del orden médico. La enfermedad y la muerte en el sanatorio son representadas en el artificial mundo del cuidado racional científico en el que no hay lugar para experiencias existenciales. Cuando estas aparecen, la novela las presenta mediadas por el humor y la permanente ironía. El amor y la muerte son sometidas así a esa abstracción y mediación formal de la norma institucional y científica con lo que se logra una neutralización del mundo real que elimina las referencias sociales y subjetivas que lo constituyen.

De acuerdo con esta interpretación, el héroe apodado "Sorgenkind des Lebens" se convierte irónicamente en palabras de Madame Chauchat en "joli bourgeois au petit endroit humide" (MANN, 2015, p. 506), que se interpreta en la obra como una 
"Sorgenkind des Lebens": cuidado, interioridad y embriaguez en La montaña mágica... María Belforte

construcción que significa lo mismo que el primer epíteto. El narrador aclara luego "cabía preguntarse qué elemento de aquella combinación tendría más peso al final: el de 'burgués' o el de la vida..." (íd.). Esta aclaración muestra humorísticamente la perspectiva de la interioridad que deja afuera la plenitud de la embriaguez para descomponer al héroe en dos esencias lejanas a la trascendencia de la vida del primer nombre: la dicotomía del burgués y su corporalidad enfermiza contiene dos componentes lejanos a la fuerza subjetiva de la interioridad que aspira a la embriaguez y a su vínculo con lo vital. En el centro del problema subjetivo se encuentra la compleja relación con el concepto de vida, que no encuentra ya refugio en la interioridad de la formación de la personalidad. En sus análisis de la República de Weimar, Eric Weitz sostiene que Mann se encuentra "atareado con dar a luz su propia clase, la Bildungsbürgertum, la clase media cultivada". Para el autor, este sector cultivado se define por "los vocablos Besitz und Bildung", y se enfrenta siempre al espectro de las masas (WEITZ, 2009, p. 301). La revisión existencial de la interioridad del héroe y el sometimiento al orden del cuidado frente al peligro de la embriaguez y el descontrol se enmarcan históricamente en la amenaza en ascenso de las reivindicaciones de las masas durante los años veinte.

\section{Conclusiones}

La novela muestra un pasaje en la transformación de la subjetividad que se desarrolla en la cultura alemana tras la derrota en la Primera Guerra Mundial y durante la República. La aspiración a una experiencia embriagadora de la subjetividad se encuentra presente en el periodo previo a la guerra y se funda en una concepción de la vida heredera de la filosofía de Nietzsche. Mann da centralidad a la noción de embriaguez al situarla en el núcleo temático de dos trabajos destacados como La muerte en Venecia y La montaña mágica, pero en este último caso, interpone una mediación racional que lo aleja de las tendencias radicales de 
"Sorgenkind des Lebens": cuidado, interioridad y embriaguez en La montaña mágica... María Belforte

otras expresiones literarias y filosóficas del período: no hay aquí ya una entrega a esa experiencia, sino una mediación. En este sentido, el estudio de la embriaguez en la obra de 1924 permite reconocer dos aspectos en tensión y en transición en el escritor: su apoyo a la República y su viraje hacia posiciones democráticas y liberales, junto a una formación derivada del vitalismo y del irracionalismo de preguerra. La idea que permite mediar estas posiciones por momentos en tensión es la de cuidado médico que se elabora conjuntamente con la emergencia del saber científico y en este caso, junto a los vestigios de concepciones nihilistas herederas de la filosofía de Nietzsche: el concepto benjaminiano de "nihilismo médico", elaborado por Benjamin en el contexto del proyecto sobre los pasajes, permite enmarcar a La montaña mágica dentro de una línea de ruptura con el concepto de interioridad proveniente de la tradición literaria del siglo XIX.

Los análisis de Bloch proponen una interpretación política que permite explicar esta tensión en la obra de Mann: elementos arcaicos presentes en la novela conviven con elementos racionales. Una concepción de la subjetividad atravesada por categorías nietzscheanas, que encuentra en nociones como la de embriaguez un fundamento metafísico, coexiste con un intento de presentación racionalista y relativista que, tras la derrota y el giro hacia la derecha durante la República, desconfía de la oscuridad de aquella tradición.

\section{Referencias}

ASCHHEIM, Steven E. Nietzsche und die Deutschen. Karriere eines

Kults. Trad. K. Laermann. Stuttgart/Weimar: Metzler, 2000.

BENJAMIN, Walter. El surrealismo. La última instantánea de la inteligencia europea. In: Imaginación y sociedad. Iluminaciones. Trad. de Jesús Aguirre. Madrid: Taurus, 1998, p. 41-62.

Gesammelte Schriften, R. Tiedemann y H. Schweppenhäuser (eds.), 7 tomos. Frankfurt /M: Suhrkamp, 1979-1989. = [GS] 
"Sorgenkind des Lebens": cuidado, interioridad y embriaguez en La montaña mágica... María Belforte

. Esquemas para un problema psicofísico. In: Sobre el amor y temas afines. Un problema europeo (Fragmentos y esquemas). Trad. María Belforte. Buenos Aires: Gorla, 2016, p. 41-54.

BLOCH, Ernst. Erbschaft dieser Zeit. Frankfurt a/M: Suhrkamp, 1973. . Poesie im Hohlraum. In: . Literarische Aufsätze. Frankfurt /M: Suhrkamp, 1984. p. 117-135.

GAY, Peter. Weimar Culture: the Outsider as Insider. Nueva York: W. W. Norton \& Company, 2001. HUFNAGEL, Edwin. Apolíneo/dionisíaco. In: NIEMEYER, Christian (org.). Diccionario Nietzsche. Conceptos, obras, influencias y lugares. Trad. de I. de De los Ríos, S. Santana, J. L. Puertas y J. Planells. Madrid: Biblioteca Nueva, 2012. p. 54-55.

LEBOVIC, Nitzan. The Philosophy of Life and Death: Ludwig Klages and the Rise of a Nazi Biopolitics. Nueva York: Palgrave Macmillan, 2013.

LUKÁCS, Georg. La tragedia del arte moderno. In: . Thomas Mann. Trad. J. Muñoz. Barcelona/México: Grijalbo, 1969a, p. 53-114.

A la búsqueda del burgués. In: Thomas Mann. Trad. J. Muñoz. Barcelona/México: Grijalbo, 1969b, p. 13-52.

MANN, Thomas. Der Zauberberg. Frankfurt a/M: Fischer, 1988. Selbstkommentare: 'Der Zauberberg'. Frankfurt a/M: Fischer Taschenbuch, 1995.

La montaña mágica. Trad. de I. García Adánez. Barcelona: Edhasa, 2015.

MAX, Katrin. Der Zauberberg. In: BLÖDORN, Andreas \& MARX, Friedhelm (orgs.). Thomas Mann Handbuch. Leben - Werk Wirkung. Stuttgart: Metzler, 2015, p. 32-42.

MOSSE, George L. La cultura europea del siglo XX. Trad. de J. M. Álvarez Flórez. Barcelona: Ariel, 1997.

NIETZSCHE, Friedrich. El nacimiento de la tragedia. Trad. A. Sánchez Pascual. Madrid: Alianza, 1977. 
"Sorgenkind des Lebens": cuidado, interioridad y embriaguez en La montaña mágica... María Belforte

OBERTHÜR, Johannes. Eros. In: NIEMEYER, Christian (orgs.). Diccionario Nietzsche. Conceptos, obras, influencias y lugares. Trad. de I. de De los Ríos, S. Santana, J. L. Puertas e J. Planells.Madrid: Biblioteca Nueva, 2012, p. 171-172.

REED, T. J. Mann and history. In: ROBERTSON, Ritchie (org.). The Cambridge Companion to Thomas Mann. Cambridge: Cambridge University Press, 2001, p. 1-21.

TRAVERS, Martin. Death, Knowledge, and the Formation of Self: The Magic Mountain. In: VAGET, Hans Rudolf (orgs.), Thomas Mann's TheMagic Mountain. A Casebook. Nueva York: Oxford University Press, 2008, p. 31-44.

VAGET, Hans Rudolf. The Making of The Magic Mountain. In: . (org.).

Thomas Mann's The Magic Mountain. A Casebook. Nueva York: Oxford University Press, 2008. p. 13-30.

WEITZ, Eric D. La Alemania de Weimar. Presagio y tragedia. Trad. Gregorio Cantera. Madrid: Turner, 2009.

WESSELL, Eva. Magic and Reflections: Thomas Mann's The Magic Mountain and His War Essays. In: ; LEHNERT, Herbert (orgs.). A

Companion to the Works of Thomas Mann. Camden House, 2004, p. 129-145. 